\title{
On the Construction of the Style of Study in Private Universities
}

\author{
Wang Qiang, Zhang Guifang, and Liu Wenbin* \\ Wuhan Technology and Business University, Wuhan, 430065, China \\ Email: 812926096@qq.com \\ *Corresponding Author
}

Keywords: private universities; the construction of the style of study; five elements

\begin{abstract}
As one of the vital part of the construction of school style, a good construction of the style of study always plays an important role when training talents. In view of the characteristics of private universities, the construction of the style of study seems more crucial. This paper based on the five main elements of the construction of the style of study: students' ideological and political education; classroom teaching; the education of university counselors; campus culture and dormitory culture construction, which have great influence on the construction of the style of study. This will be an effective approach to promote the construction of the style of study if applying these five elements undoubtedly.
\end{abstract}

\section{Introduction}

The construction of the style of study not only plays a guiding role in students' daily life, but also indicates their future development prospects. More importantly, it is directly related to the revitalization of the country and the prosperity of the nation. The construction of the style of study not only depends on the learning attitude, the learning methods and the learning spirit of the educated, but also relies on the teaching attitude, teaching methods and teaching spirit of the educator. Meanwhile, school's teaching facilities, running conditions and cultural atmosphere are of great importance. This paper focuses on such elements: ideological and political education, classroom teaching, the education of university counselors, campus culture and dormitory culture construction, which have great impact on the construction of the style of study.

\section{Make efforts to the student's ideological education on the basis of their characteristics}

The construction of students' ideological and political education is the essence of the construction of the style of study. Compared to the students from key or ordinary universities, the students from independent colleges or junior colleges may show some differences in their thought and even deeper levels of thinking. For instance: some of the students have relatively weak basic knowledge and poor learning habits, they are not hard-working at the same time. Thus, they may have less interests in some entertainment, knowledge or science and technology activities. A few students even want to get the diploma without making any efforts instead of studying hard, which leads to their failures in graduation. Some students possess relatively good family economic status, so they are less likely to be hard-working. They are even a little bit selfish, and have weak collective ideas. And some students haven't acquired systematical basic civilization education. Lack of integrity, weak ability of self-discipline and self-care are their typical features. The above mentioned all have effects on the construction of the style of study in various degrees. Since the subject of an university's construction of the style of study is the college students, it's fundamental to maximize the main function of the students in the process of the construction of the style of study.

\subsection{Correct learning motivation, improve the internal drive of study}

Motivation is a kind of inherent factor which can promote people to take actions in order to 
achieve a certain purpose for needs. It helps people to acquire knowledge, skills and norms of behavior purposely and systematically. As a result, the students' learning enthusiasm mainly lies on their learning motivations and interests from the perspective of psychological factors. Obviously, positive learning motivation will improve the learning enthusiasm accordingly. Being serious, attentive and nervous, having strong interests and attention are the signs. The continuous enhancement of the correct learning motivation is the internal drive of study, which can promote the students' learning. College students' learning motivation is an interaction combined with multiple factors and component. Various factors have the leading position in different stages. There are two aspects of this motivation. On the one hand, the internal motivations come from students' ideals, aspirations, interests and desires, such as: vitalizing the country, having a sense of self-esteem and a sense of achievement, looking for jobs and loving their majors. That will lead the students to study consciously with stability and durability. On the other hand, the external motivation caused by external conditions, such as: the competition between classmates, the discipline restraint in school, the pressure by parents will also help the students to promote their study. And the characteristics of the young determines its instability and transience. As a result, it is necessary to combine the internal motivations and external motivations together to strengthen the construction of the style of study and create a better learning atmosphere by activating the external and intensifying the internal through management. At the same time, the school should attach importance to the national history education, educate the students to be clear to the position, pursuit and prospects of their majors, and guide them to set up goals to enhance their sense of achievement and enterprise.

\subsection{Cultivate volitional quality, promoting self-management}

The essence of life lies on pursuit and perseverance. Educating the students to know the significance of perseverance can not be ignored in the construction of the style of study. Students with persistence and willpower will work persistently after establishing their goals, and they are also very good at overcoming the interference of the disadvantaged factors that affect the process of the achieving the goal. Since the young people lack of society experience and the power of self-control with the mood changes dramatically, it is easy for them to get into some bad habits. The craze for martial art novels, videos and cyber bars in campus have bad impacts on the construction of the style of study, which reflects the students' weak will, poor self-control and bad persistence rather than the characteristics of the students. Therefore, we should make a combination of environmental cultivation and standardized management, and promote both supervision and motivation. Then we should formulate a regular timetable, and carry out some practice activities to improve students' ability of self-control and develop the good qualities.

\subsection{Encourage the underachievers, reverse the disadvantaged factors}

As one part of the private university's construction of the style of study, the underachiever's style of study will directly determine the result of the overall construction, whether it's a success or a failure. The underachiever's study-weariness mainly comes from their fear and lack of confidence. According to psychology, success can help people to build confidence while failure weaken that, and the confidence of learning directly influences the learning interest and learning behavior. If one has constantly failed in learning, he would have lost his confidence inch by inch. Then his sense of achievement in learning will disappear, accompanied with the weariness of learning, he will tend to enjoy himself with feasting and other kinds of entertainment instead of focusing on study. That will affect the students around with no doubt. Therefore, the underachievers should be received more care and help, and teachers should educate them and protect their self-confidence rather than ignore them and leave them behind. What's more, teachers should help them to set the target correctly, which starts with simple target and then to difficult one. And the underachievers will gradually build up confidence and grow up in a healthy way.

\section{Implement every procedure in classroom teaching on the basis of teaching characteristics}


objectives and the characteristics of the students, the private universities should mainly focus on developing students' application skills, which means the private universities carry a particular historical mission and time requirement in teaching. In other word, if private universities apply the teaching mode from the key or ordinary universities mechanically and use the mode to organize their teaching activities, the students in private universities will not reach the expected goal both in research ability and application skills compared with the students in key or ordinary universities. Then, the construction of classroom teaching led by educators is one of the most effective ways to improve the learning interest of the educated, which can also increase their sense of learning identity. That is the key to the construction of the style of study in private universities. A harmonious teaching atmosphere is conducive to the mutual understanding between teachers and students, to benefit teachers as well as students in learning, and to increase the trust between them. In this way, we should create a nice classroom teaching atmosphere in order to promote the reform of teaching materials for private university students and to explore and improve the examination rules of private universities, which has achieved a multiplier effect on the process of the construction of the style of study.

\subsection{The improvement of the quality of teachers is the premise}

As the guider in teaching activities, teachers are undertaking two obligations: teaching and educating students. What's more, they should also shoulder the responsibility of building socialist builders and successors. Therefore, teachers are required not only profound knowledge and rigorous attitude, but also a strong sense of responsibility. They need to keep energetic in class all the time. Adolf Diesterweg, a very famous German educator, once pointed out: "The philosophy of teaching is encouragement and inspiration instead of teaching knowledge and skills only. How can a teacher inspire the students without excitement? And how can a teacher awake the sleepy students without enthusiasm? Only when the teacher have passion, the class will stay active. Otherwise, the lesson will lack of vitality." So, the teachers should be accustomed to stay passionate and energetic as possible as they can. As a result, it is required to carry out more training for the educators. And they should continue to improve their own self-cultivation at the same time. In this way, they will influence the students with their charming personality.

\subsection{The improvement of the teaching methods is the guarantee}

Adopting some appropriate and flexible methods to mobilize the students and to improve their attention and enthusiasm. If a teacher just teaches according to the textbook completely and ignores whether the students have understood or not, the student's interests and subjective initiative must have been weaken accordingly. Choose the thoughts of heuristic education to attract more students to participate in. Improve students' attention through Q \& A. Develop students' learning initiative by teaching good learning methods and thinking patterns. Increase the attractiveness of teaching with teaching aids. And a nice teaching atmosphere will be formed.

\subsection{The reform of the teaching materials tend to be suitable for the students}

It's worthwhile to think about the reform of teaching materials and it's urgent to make the materials more suitable for the students in private universities. That's the key to carry out the principle of teaching students in accordance with their aptitude. Because the private university students have relatively poor learning foundation when they are enrolled in school, and the private universities' main objective is to train and develop skilled talents, so it is imminent to push forward the textbook reform of private universities. During the process, it's significant to balance theory and practice, and grasp the difficulty level of the teaching materials according to the characteristics of students and the training objectives. Then we can gradually improve the students' interest in learning and finally achieve the purpose of helping them to take the theory into practice. Only in this way, can we complete the training target of the private university better. At present, only a few private universities have made some progress in the reform of teaching materials, efforts still need to be made. 


\subsection{The exploration of better examination rules}

The exploration and improvement of the examination rules is another important aspect of promoting the construction of the style of study for the private university. The poor foundation of students leads to the low passing rate of examinations, which causes some students to have the "test phobia", they will feel extremely nervous and fearful for the exams. If the guidance is improper, a series of vicious cycles is possible to happen. I put forward a new rule of examination called "Designing Different Test for Different Level Students". According to the needs of students in different levels, the teacher design different test papers for different level students. Simply speaking, the teacher can design three kinds of test papers: A, B and C. The difficult level of them are not the same. The test paper with "A level" is the most difficult, "B level" is the lower than "A level", and "C level"is the lowest. The marking rules are different clearly. The grades for "A level" rank from 80 to 100 points, the grades for "B level" rank from 70 to 80 points, and 60 to 70 points for the students choose "C level" no matter how perfect they have done. Finally, based on the students' voluntary choice, the division test will be carried out. "Designing Different Test for Different Levels", this kind of new rule of examination can make the students understand the importance of study and get interests to study gradually, which can also achieve the purpose of teaching students in accordance with their aptitude. Some private universities have been using the credit mechanism for test until now. It is adaptable to adopt this new rule of examination as a supplementary mechanism.

\section{Educate the students on the basis of university counselors characteristics}

The education and instruction of university counselor is fundamental to the construction of the style of study. Except the traditional ideological and political education, future career planning, psychological counseling and employment services are all what university counselors need to offer. The university counselors are required to apply the training objectives for private universities, and have better practical abilities. To guide students, serve students and affect students with their own words and actions, and to help students carry out extracurricular activities. It's required to let the university counselors to live in the same environment with the students and communicate frequently with each other in private universities, which is quite different from that of public ones. This kind of requirement has several advantages: the university counselors can have a better knowledge of the students' abilities; they can also get a clear idea of the students' psychological characteristics to understand them. In this way, the communication between the university counselor and the students will be more and more after class; the distance between them will be smaller and smaller in life. Being the student's teacher when teaching, while being their friends in life. That will help the university counselors to obey the law of teaching and to create a good teaching atmosphere. Obviously, besides educating and instructing the students, universities counselors should also take advantage of all favorable opportunities to enhance their ideological and political theory accomplishment, and continue to acquire more professional and non-professional knowledge, so as to really keep pace with the times. At present, for the employment of university counselors in some private universities, the young people are more and more respected, especially the outstanding undergraduate or graduate students who have the students' cadres experience. Because they've just graduated from school, so there is no age gap between the students and them. And they can know the young student better for putting themselves in the students' shoes when deal with daily affairs. Besides that, they can get better understanding and in support of the students for managing the students in a humanized mode. These are all good to promote the improvement of the style of study. As an important element in the construction of the style of study, university counselors' education can’t be ignored. The selection of counselors is worth considering for private universities.

\section{Creating a good campus culture to complement the construction of the style of study}

The construction of campus culture will promote the development of the construction of the style 
of study. Because the influence of campus culture on college students is of potentiality and irresistibility. As the saying goes: "With the breeze sneaking into the tranquil night, it nurtures every spring life spontaneously and silently." A positive campus culture cultivates the student's sentiment slightly and enhances the students' self-education and self-management ability. Learning in a positive cultural atmosphere, the students' sentiment will be affected. It is easy to arouse their ambition and competitiveness, improve their interest in learning, and facilitate the formation of a good academic atmosphere. A good campus culture is beneficial to the growth of the students. As a new mode of higher education, campus culture construction of private universities is still in the initial stage. Therefore, many problems need to solve: fragment of campus spirit, vague in management philosophy, lag in campus construction, simplicity of cultural activities, etc. In order to solve these problems, we need to improve the understanding of the importance of the construction of campus culture and to solid the basic work according to the present private universities' campus culture situation. It's better not to be ambitious, we need to make the campus culture better and promote the construction of study style in private university gradually.

\subsection{The guarantee: to enhance the construction of institutional culture}

The system is the premier to the construction of campus culture, the establishment of efficient and orderly management mechanism of the college is the institutional guarantee for the construction of campus culture. Establishing a "management means services" concept, and striving to build a "learning organization". What's more, we should also stress and study the philosophy of management to form a good atmosphere of leadership, and foster the consciousness of striving for excellence. The people-oriented principal, a scientific and systematic construction of the system, the democratization of schools' major decisions are what we need to insist and promise. In addition, to formulate the rules and regulations of schools for students and teachers mutual benefit is an important step.

\subsection{The premise: to enhance the construction of spiritual culture}

Based on the background of professional knowledge, a large number of extracurricular scientific activities should be carried out. Let the students understand the concept of running a college from activities, and guide them to study hard and diligently on the purpose of becoming all-round talents. The various extracurricular scientific and technological activities require not only solid professional knowledge, but also reasonable and intelligent structure, which is bound to promote students to improve their knowledge structure and stimulate their learning enthusiasm. We should develop more activities about culture, sports and art with distinctive characteristics and wide participation. In addition, we should create track and field games, singing competitions, new year parties, Spring Festival parties, dormitory culture festival and other stylistic activities, so as to enrich the cultural life of teachers and students. The Challenge Cup for National College Students' Extracurricular Academic Competition of Science and Technology has launched a boom in loving and pursuing science among Chinese university students since 1980s. And it has been highly valued by private universities.

\subsection{The foundation: to enhance the construction of behavior culture}

Actually, some of the private university students lack of hard-working quality in different degrees: they don't want to do the tiring and tough things. So, they won't try to study hard, or even won't take difficult job into consider. This is becoming an indispensable subjective factor to the current employment situation. Being dishonest in life is not unusual of the students for their poor sense of integrity. Copy the homework, cheat in exams, or even lie to the university counselor when asking for a leave or when applying for the needy students have all occurred from time to time. More worryingly, college student are indifferent to these dishonest behaviors. Therefore, guiding the private university students to have good behaviors and habits is another important task for campus culture construction of private universities. 


\section{Combined with material resource and spiritual education to manage student dormitory}

The construction of the dormitory culture is another element of the construction of the style of study. As an important place for students to learn, live and rest, the dormitory is an important window to reflect the spirit of the students. In fact, the construction of good dormitory culture plays a positive role in guaranteeing the construction of excellent style of study, whose importance has been paid more and more attention by most private universities.

\subsection{Creating a clean and harmonious learning environment by focusing on the management}

A strict management is very important to let the students to develop a good habit and ensure they will have plenty of time and energy into the study. The dormitory is an important place for students to make their body and mind feel cozy. The excess energy will be released by relaxing their body and mind. If there is no strict management, "chatting til midnight" will inevitably affect the students' daytime learning. Thus, sticking to a regular study and rest system and having a good lifestyle is very important, not only for the needs of the healthy development of the body, but also for the requirement of knowledge and skills. Exercising and reading in morning, having a nap in the noon, insisting self-study in the evening and going to sleep at bedtime, etc. If these rules are obeyed effectively, the normal teaching order will conduct well.

\subsection{Creating a clean and harmonious dormitory environment by increasing the students emotion quotient}

A clean and orderly dormitory environment is conducive to the training of a positive and optimistic habit of living, even to the cultivation of a noble spirit. In contrast, a dirty and messy dormitory environment is possible to develop a sluggish life style, which isn't good for the improvement of the learning efficiency. Compared to the classroom teaching, the dormitory culture construction plays an irreplaceable role. For instance: example publicity, celebrity motto, dormitory competition, Party member dormitory rating, etc. They can all stimulate the emotional world of college students and have a great impact on improving their emotion quotient(EQ). And it is correct to adjust the life of the dormitory by carrying out various and positive evaluation, such as culture construction competition and the dormitory decoration competition.

\subsection{Offering the material resource by equipping with necessary service facilities}

The physical environment is the material basis of higher education activities. Offering good and enough material resources is quite important to the learning environment in campus. Therefore, to create a good dormitory material environment at most and to provide good material conditions for the students will promote the construction of good style of study undoubtedly.

\section{Acknowledgments}

This research was supported by special subject of educational informatization of Higher Education Society in China (Grant No. 2016XXYB22).

\section{References}

[1] Xu Bocai, The exploration and Research on the Ideological and Political Education of College Students (2008)

[2] Sun Xiaobin, Study on the Organization and System of Private Education in China (2008)

[3] Jing Lu. Application of interactive whiteboard in College Classroom Teaching[J]. Audiovisual Education in China,2011(13):83-85.

[4] Shaochun Zhong. An overview of the development of information technology and curriculum integration in the past ten years[J]. Information Technology Education in China.2010(21):11-13.

[5] Khalid, A. B. Barriers to the Successful Integration of ICT in Teaching and Learning Environments: A Review of Mathematics, Science \& Technology Education, 2009(3):235-245. 